\title{
The Effect Of NO Donor on Calcium Uptake and Reactive Nitrogen Species Production in Mitochondria
}

\author{
Olga Akopova ${ }^{a}$ Anatoly Kotsiuruba ${ }^{a}$ Yulia Korkach ${ }^{a}$ Liudmila Kolchinskaya ${ }^{a}$ \\ Valentina Nosar $^{b}$ Bronislav Gavenauskas ${ }^{b}$ Zoya Serebrovskab ${ }^{b}$ Iryna Mankovskab \\ Vadim Sagach ${ }^{\mathrm{a}}$
}

aCirculation department, Bogomoletz Institute of Physiology, NAS of Ukraine, Kiev, ${ }^{\text {bHypoxic states }}$ department, Bogomoletz Institute of Physiology, NAS of Ukraine, Kiev, Ukraine

\section{Key Words}

Mitochondria $•$ Nitric oxide $•$ Nitroglycerine $\cdot$ Calcium $•$ Mitochondrial NO synthase $•$ Reactive nitrogen and oxygen species - Permeability transition pore

\begin{abstract}
Background/Aims: NO and reactive nitrogen species (RNS) are thought to be physiologically important effectors of mitochondrial calcium transport, but this issue was not studied in a living organism. According to literature, the modulation of $\mathrm{Ca}^{2+}$ uptake could influence RNS production via the action on mitochondrial NO synthase (mtNOS). The aim of this work was to study the effect of in vivo administration of NO donor nitroglycerine (NG) on matrix $\mathrm{Ca}^{2+}$ accumulation, RNS production and mtNOS activity. Methods: $\mathrm{Ca}^{2+}$ uptake was studied spectrophotometrically with arsenazo-III. The amounts of stable RNS (nitrite, nitrate and nitrosothiols) and L-citrulline, the product of enzymatic NOS activity, were determined analytically. Results: NG administration resulted in dose-dependent short-term increase in $\mathrm{Ca}^{2+}$-uptake accompanied by essential rise in L-citrulline and RNS content in mitochondria. In parallel, dose-dependent elevation of hydroperoxide production was detected. $\mathrm{Ca}^{2+}$ uniporter activity was not affected, but mitochondrial permeability transition pore (MPTP) was effectively blocked by NO. Conclusion: Our results indicate that MPTP blockage by NO was the primary cause for the increase in calcium uptake which eventually resulted in the activation of mtNOS and RNS production. Improved $\mathrm{Ca}^{2+}$ accumulation in mitochondria, together with MPTP blockage, may contribute to well-known cardioprotective effects of pharmacological donors of nitric oxide.

(C) 2016 The Author(s)

Published by S. Karger AG, Basel
\end{abstract}

\section{Introduction}

Wide spectrum of cardioprotective actions of nitric oxide (NO) and pharmacological NO donors includes the activation of soluble guanylate cyclase and cGMP-dependent modulation of ion channel activity in plasma membrane and sarcoplasmic reticulum which eventually 
reduce the level of cytosolic calcium and serve cardioprotective effects [1, 2]. In agreement with contemporary knowledge, mitochondria play important role in modulation of cytosolic calcium dynamics [3-5]. Several diseases are accompanied by the impairments of both cellular and mitochondrial $\mathrm{Ca}^{2+}$ homeostasis [3-6]. However, thus far little is known of the NO action on mitochondrial handling calcium.

Based on the studies in vitro [7-9], NO is thought to be physiologically important effector of calcium accumulation via potential-dependent channel of inner membrane, mitochondrial $\mathrm{Ca}^{2+}$ uniporter [4]. The data obtained with different respiratory substrates showed the release of $\mathrm{Ca}^{2+}$ after the loss of membrane potential $\left(\Delta \Psi_{\mathrm{m}}\right)$ in mitochondria exposed to NO [7, 8]. Besides, it was shown that prevention of $\mathrm{Ca}^{2+}$ uptake, because of the inhibition of respiratory chain by $\mathrm{NO}$ and membrane depolarization, blocked the opening of mitochondrial permeability transition pore (MPTP) [9], the megachannel involved in triggering cellular death.

MPTP is composed of mitochondrial membrane proteins and opened by $\mathrm{Ca}^{2+}$, phosphate and oxidants; its role in pathogenesis of several diseases was well documented in the literature $[10,11]$. However, MPTP structure since its discovery was debated. Initially, membrane proteins - adenine nucleotide translocase (ANT), voltage dependent anion channel, and matrix protein - cyclophillin D, were considered to be the main MPTP components [10]. But in the light of very recent findings, it was proposed that MPTP is formed by dimerization of $\mathrm{F}_{0} \mathrm{~F}_{1}$ ATP synthase, c-subunit of which being the main pore-forming component [11], and cyclophillin D playing minor regulatory role $[4,11]$.

Based on the above reports, it is reasonable to suppose that NO would affect $\mathrm{Ca}^{2+}$ uptake in mitochondria of a living organism, but thus far little is known about the action of NO on mitochondrial handling calcium in vivo. One of the most important consequences of NO targeting the $\mathrm{Ca}^{2+}$ transport system of mitochondria could be the modulation of cytosolic and matrix levels of calcium [4,5], which is intimately coupled to reactive nitrogen and oxygen species (RNS and ROS) production.

There is plenty of evidence of the crosstalk between nitric oxide, calcium and ROS in mitochondria (reviewed in [12-14]). According to literary data, mitochondria are the potent source of cellular ROS and RNS $[15,16]$. The main sources of ROS are the respiratory chain and several oxidoreductases localized into matrix and intermembrane space [16]. mtNOS is considered to be the main source of RNS $[14,15]$, but devoid of the substrate L-arginine and the cofactor tetrahydrobiopterine, it would produce superoxide [17]. Calcium, which enters the matrix via $\mathrm{Ca}^{2+}$-uniporter [18], is the effector of several mitochondrial enzymes, such as ATP-synthase, some dehydrogenases of tricarbonic acid cycle, mitochondrial NO synthase (mtNOS) $[13,15,19]$, many of which are capable of producing ROS and RNS. Accordingly, studies in vitro have shown that mitochondrial nitric oxide synthase (mtNOS) activity was dependent on $\mathrm{Ca}^{2+}$ accumulation [20]. This allows an assumption that modulation of $\mathrm{Ca}^{2+}$ uptake in vivo likewise might result in the modulation of mitochondrial reactive nitrogen species (RNS) production.

Although already studied by many authors on different cell models and isolated mitochondria, molecular mechanisms of the crosstalk between nitric oxide and calcium uptake in mitochondria and its physiological role are far from being clear. Successful applications of NO donors in clinic need a careful study of these processes in a living organism, but this topic was not addressed under physiological conditions. Thus the aim of this work was to estimate the effect of NO on mitochondrial calcium uptake and RNS production in vivo under administration of the widely used NO donor nitroglycerine.

\section{Materials and Methods}

Animals

All procedures performed in studies were in accordance with EU directive 86/609/EEC and the ethical standards approved by the Ethics Committee at A.A. Bogomoletz Institute of Physiology, NAS Ukraine. Adult 


\section{Cellular Physiology Cell Physiol Biochem 2016;39:193-204 \\ \begin{tabular}{l|l} 
and Biochemistry 10.1159/000445616 & $\begin{array}{l}\text { (c) 2016 The Author(s). Published by S. Karger AG, Basel } \\
\text { www.karger.com/cpb }\end{array}$ \\
\hline Published online: June 24, 2016
\end{tabular} \\ Akopova et al.: NO Affects Calcium Uptake and RNS Production in Mitochondria In Vivo}

Wistar rats with 180-200 g body weight were used. Nitroglycerine (NG) was administered intraperitoneally at the doses $0.25,0.5,1.0$ and $1.5 \mathrm{mg} / \mathrm{kg}$ weight. Control animals were administered physiological solution.

\section{Isolation of mitochondria}

Mitochondria were isolated by the standard procedure. Hearts and liver removed 5 and 30 min after $\mathrm{NG}$ administration were thoroughly washed with $0,9 \% \mathrm{KCl}\left(2^{\circ} \mathrm{C}\right)$ minced and homogenized in standard isolation medium: $250 \mathrm{mM}$ sucrose, $20 \mathrm{mM}$ Tris-HCl buffer, $1 \mathrm{mM}$ EDTA, pH 7.4. Homogenate was centrifuged $7 \mathrm{~min}$ at $700 \mathrm{~g}$ and, after removal of the pellet, $15 \mathrm{~min}$ at $11,000 \mathrm{~g}$. The sediment was resuspended in a small volume of EDTA-free medium and stored on ice. The protein content was determined by the method of Lowry.

\section{Calcium transport study in isolated mitochondria}

$\mathrm{Ca}^{2+}$ transport was studied in the incubation medium: $120 \mathrm{mM} \mathrm{KCl}, 5 \mathrm{mM}$ sodium succinate, $1 \mathrm{mM}$ $\mathrm{KH}_{2} \mathrm{PO}_{4}, 5 \mathrm{mM}$ Tris- $\mathrm{HCl}$ buffer, $\mathrm{pH} 7.4$ in the presence of $50 \mu \mathrm{M}$ of $\mathrm{Ca}^{2+}$ indicator arsenaso-III. $\mathrm{CaCl}_{2}$ was added into incubation medium. $10^{-6} \mathrm{M}$ of cyclosporine $\mathrm{A}$ and $10^{-5} \mathrm{M}$ of ruthenium red were added dependent on conditions. Starting from the addition of mitochondria ( $0.5 \mathrm{mg}$ protein), $\mathrm{Ca}^{2+}$-uptake was monitored by standard dual-wavelength technique [9], and the absorption of mitochondrial samples at wavelengths pair 654 and $700 \mathrm{~nm}$ was registered.

\section{Membrane potential measurement}

Membrane potential $\left(\Delta \Psi_{\mathrm{m}}\right)$ was monitored spectrophotometrically [21] with the use of $10 \mu \mathrm{M}$ safranine as membrane potential probe in the same incubation medium. Dual-wavelength technique was used [21], and absorption of mitochondrial samples at wavelengths pair 510 and $525 \mathrm{~nm}$ was registered. Complete membrane depolarization was verified by the addition of $10^{-6} \mathrm{M}$ CCCP. Difference between the absorbanse of deenergized and fully energized mitochondria was taken for $\Delta \Psi_{\mathrm{m}} ; \Delta \Psi_{\mathrm{m}}$ registered in mitochondria of control animals was taken for $100 \%$.

\section{The study of RNS production and mtNOS activity}

RNS production was estimated by the determination of stable metabolites content: nitrite, nitrate and $S$-nitrosothiols. Mitochondrial NOS activity was estimated by measuring L-citrulline content in mitochondrial extractions. For the determination of metabolite content in mitochondrial preparations aliquots of mitochondrial suspensions were sampled and protein was removed by the addition of $0.5 \mathrm{M}$ $\mathrm{HClO}_{4}$ with consequent precipitation $10 \mathrm{~min}$ at $10,000 \mathrm{~g}$. After the pellet was discarded, supernatant was neutralized by the additions of $5 \mathrm{M} \mathrm{KOH}$ and centrifuged repeatedly $5 \mathrm{~min}$ at 10,000 g. Protein-free extracts were used for the metabolite analysis.

\section{Nitrite content}

Nitrite content was determined by the method of Green with the Griess reagent [22]. Griess reagent was prepared by mixing equal volumes of $0.1 \%$ water solution of $N$-(1-naphthyl)ethylenediamine dihydrochloride with $1 \%$ sulfanilamide in $5 \% \mathrm{H}_{3} \mathrm{PO}_{4}$ just before use. $0.5 \mathrm{ml}$ aliquots of mitochondrial protein-free extractions were sampled and mixed with Griess reagent in a proportion 1:1 by volume. 5 min after absorbance at $546 \mathrm{~nm}$ was measured; nitrite concentration was determined from calibration curves.

\section{The determination of nitrate}

Nitrate was determined by the method based on the reduction of $\mathrm{NO}_{3}{ }^{-}$to $\mathrm{NO}_{2}{ }^{-}$by zinc [23]. For the determination of the summary content of $\mathrm{NO}_{2}{ }^{-}+\mathrm{NO}_{3}{ }^{-} 1.0 \mathrm{ml}$ aliquots of the protein-free preparations at $\mathrm{pH}$ 7.4 were mixed with $50 \mu \mathrm{l}$ of zinc suspension $\left(100 \mathrm{mg} \cdot \mathrm{ml}^{-1}\right.$ in water). After 5 min centrifugation $0.5 \mathrm{ml}$ of the supernatants were sampled and mixed with equal volume of the Griess reagent; after that absorbance at $546 \mathrm{~nm}$ was measured. For the determination of nitrate content, that of nitrite, established in parallel missing the reduction procedure, was subtracted.

S-nitrosothiols content

Total $S$-nitrosothiol content was determined by the method of Saville [24], using Griess reagent with $\mathrm{HgCl}_{2}$ for $S$-nitrosothiol decomposition. Briefly, $\mathrm{HgCl}_{2} /$ sulfanilamide solution was prepared by 


\section{Cellular Physiology Cell Physiol Biochem 2016;39:193-204

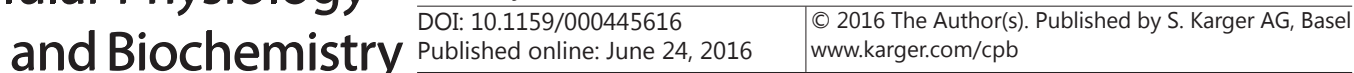 \\ Akopova et al.: NO Affects Calcium Uptake and RNS Production in Mitochondria In Vivo}

mixing 1 volume of $1 \% \mathrm{HgCl}_{2}$ in water with 4 volumes of $3.4 \%$ sulfanilamide in $0.4 \mathrm{M} \mathrm{HCl} .0 .5$ ml aliquots of mitochondrial suspensions, were added to $0.7 \mathrm{ml} \mathrm{HgCl}_{2} /$ sulfanilamide solution and $5 \mathrm{~min}$ after mixed with $0.1 \% \mathrm{~N}$-(1-naphthyl)ethylenediamine dihydrochloride in $0.4 \mathrm{M} \mathrm{HCl}$ in a proportion 2:1 by volume. Control probes were treated as above but without $\mathrm{HgCl}_{2}$. After protein removal by centrifugation and the neutralization of the probes, absorbance at $546 \mathrm{~nm}$ was measured. $S$-nitrosothiol content was determined from the increment in nitrite concentration respective to controls using calibration curves.

\section{The determination of L-citrulline}

The determination of L-citrulline was carried out according to the method described by Buga et al. [25]. Because the urea intervenes in L-citrulline determination with diacetyl monoxime [25], the samples were previously freed of it by incubating the probes with the urease. For this purpose $170 \mu \mathrm{l}$ aliquots of proteinfree samples were added to $30 \mu \mathrm{l} 50 \mathrm{mM}$ triethanolamine/HCl buffer containing urease at 1 activity unit and incubated $15 \mathrm{~min}$ at $25^{\circ} \mathrm{C}$ [25]. After that $1 \mathrm{ml}$ of the solution made of 1 part of $3 \%$ diacetyl monoxime in ethanol and 29 parts of the mixture of sulfuric and phosphoric acids in a proportion: 1 part of $\mathrm{H}_{2} \mathrm{SO}_{4}, 3$ parts of $\mathrm{H}_{3} \mathrm{PO}_{4}, 7$ parts $\mathrm{H}_{2} \mathrm{O}$ was added to the probes. Reaction mixture was held for 30 min on a water bath $\left(100^{\circ} \mathrm{C}\right)$ and cooled. Absorbance at $492 \mathrm{~nm}$ was recorded. The concentration of L-citrulline was found from the calibration curves.

\section{$\mathrm{H}_{2} \mathrm{O}_{2}$ production}

The method for $\mathrm{H}_{2} \mathrm{O}_{2}$ determination was based on the indirect registration of $\mathrm{H}_{2} \mathrm{O}_{2}$ consumption in the course of iodide $\left(\mathrm{I}^{-}\right)$oxidation to iodine $\left(\mathrm{I}_{3}^{-}\right)$in the presence of excess lactoperoxidase, the stoichiometric ratio between $\mathrm{H}_{2} \mathrm{O}_{2}$ consumption and $\mathrm{I}_{3}{ }^{-}$formation being 1:1 [26]. Aliquots of mitochondrial protein-free extractions were incubated in $2 \mathrm{ml}$ of incubation medium which contained $0.1 \mathrm{M} \mathrm{KI}$ in the presence of the excess lactoperoxidase $\left(0.5 \mu \mathrm{g} \cdot \mathrm{ml}^{-1}\right)$ in $0.05 \mathrm{M}$ Tris buffer, $\mathrm{pH} 7.33\left(25^{\circ} \mathrm{C}\right) . \mathrm{I}_{3}{ }^{-}$formation was followed spectrophotometrically at $353 \mathrm{~nm}$ and the amount of hydroperoxide was determined using molar absorption coefficient $26,000 \mathrm{~mol}^{-1} \cdot \mathrm{cm}^{-1}$.

\section{Materials}

Cyclosporine A, ruthenium red, arsenaso-III were of "Fluka" (Switzerland); nitroglycerine, sodium nitroprusside, CCCP, safranine, $N$-(1-naphthyl)ethylenediamine dihydrochloride, sulfanilamide, lactoperoxidase, urease, diacetyl monoxime, and other reagents were of "Sigma" (USA).

\section{Statistical analysis}

The data were expressed as mean \pm S.E. of 4-6 independent experiments. Statistical analysis was performed using paired Student's t-test; $\mathrm{P}<0.05$ was taken as the level of significance.

\section{Results}

Short-term effect of nitroglycerine on $\mathrm{Ca}^{2+}$ uptake and $\mathrm{NO}_{3}^{-}$formation in mitochondria

According to the data obtained, NG administration resulted in remarkable modulation of mitochondrial $\mathrm{Ca}^{2+}$-uptake. The ability of mitochondria to take up calcium $\left(\mathrm{Ca}^{2+}\right.$ accumulation capacity) was estimated as the highest amount of $\mathrm{Ca}^{2+}$ taken up by mitochondria after the addition of increasing amounts of $\mathrm{CaCl}_{2}$. The dose- and time-dependent effects of $\mathrm{NG}$ on $\mathrm{Ca}^{2+}$ accumulation capacity of mitochondria were observed (Fig. 1A, B). Rapid increase in $\mathrm{Ca}^{2+}$ uptake in rat heart and liver mitochondria took place at once after NG administration with peak effect at $0.5-1.0 \mathrm{mg} \cdot \mathrm{kg}^{-1}$ body weight (Fig. 1A, B, bars 1 ). The effect weakened $30 \mathrm{~min}$ later (Fig. 1A, B, bars 2).

The rise in calcium uptake was accompanied by the activation of RNS production. The amount of nitrate, the end product of NO oxidation, exhibited similar dose- and timedependent effects of NG in heart and liver mitochondria (Fig. 1C, D). Thus, nitrate content in heart mitochondria rose from $0.04 \pm 0.01$ to $1.4 \pm 0.015 \mu \mathrm{mol} \cdot \mathrm{mg}^{-1}$, with subsequent decrease to $0.13 \pm 0.01 \mu \mathrm{mol} \cdot \mathrm{mg}^{-1} 30 \mathrm{~min}$ after the drug administration (Fig. $1 \mathrm{C} 1,2$ ). Similar data were obtained in liver mitochondria (Fig. 1D) where the nitrate level at first rose from 0.035 
Fig. 1. The effect of $\mathrm{NG}$ on $\mathrm{Ca}^{2+}$ uptake (A, B) and $\mathrm{NO}_{3}^{-}$formation (C, D) in rat heart and liver mitochondria. $\mathrm{Ca}^{2+}$ uptake in $\mathrm{nmol} \cdot \mathrm{mg}^{-1}$ and $\mathrm{NO}_{3}{ }^{-}$content in $\mu \mathrm{mol} \cdot \mathrm{mg}^{-1}$ in mitochondria was determined 5 (1) and 30 (2) min after NG administration. $\mathrm{Ca}^{2+}$ uptake was determined as the peak amount of $\mathrm{Ca}^{2+}$ taken up by mitochondria. The data were expressed as a mean \pm $\mathrm{SE}(\mathrm{M} \pm \mathrm{m}, \mathrm{n}=6) ; \mathrm{p}<$ 0.05 was considered to be statistically significant relative to control $\left({ }^{*}\right)$; relative to data collected at $5 \mathrm{~min}$ (\#).

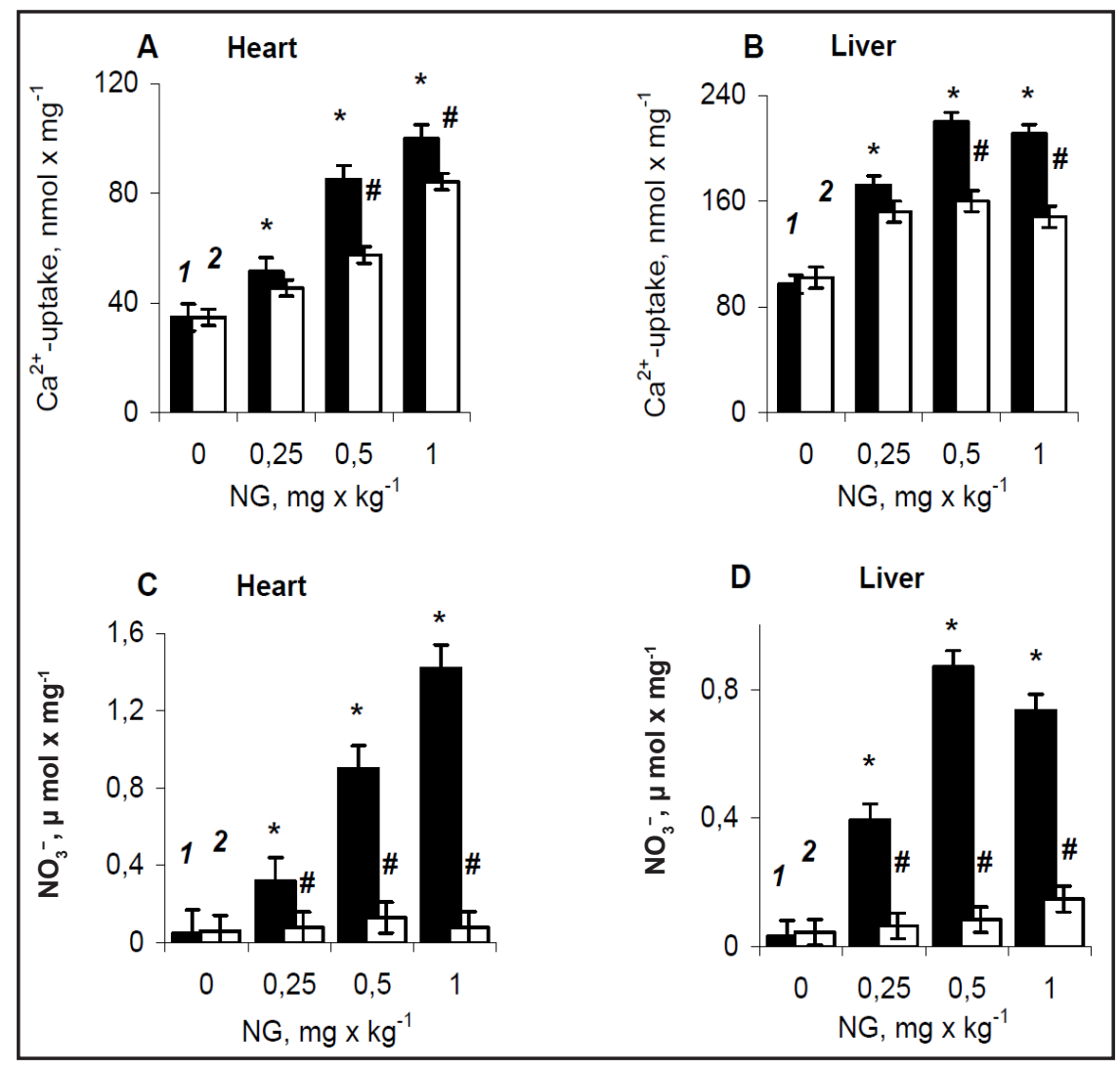

\pm 0.01 to $0.90 \pm 0.01 \mu \mathrm{mol} \cdot \mathrm{mg}^{-1}$ and then declined to $0.17 \pm 0.015 \mu \mathrm{mol} \cdot \mathrm{mg}^{-1}$. Dramatic rise in $\mathrm{NO}_{3}{ }^{-}$content in mitochondria and its decline with time indicated fast short-term activation of RNS metabolism under the action of pharmacological donor of NO.

\section{The effect of nitroglycerine on RNS and ROS production in mitochondria}

The above assumption was verified further by determining the amount of other NO metabolites - nitrite and $S$-nitrosothiols. Thus, $5 \mathrm{~min}$ after NG administration, in heart mitochondria nitrite content rose from $8.0 \pm 0.7$ to $20.0 \pm 2.0 \mathrm{pmol} \cdot \mathrm{mg}^{-1}$, whereas total $S$-nitrosothiol content simultaneously rose from $0.70 \pm 0.03$ (the basal level) to $1.50 \pm 0.09$ $\mathrm{nmol} \cdot \mathrm{mg}^{-1}$ (Fig. 2A, B, 1). The data obtained in liver mitochondria resembled those in heart mitochondria (Fig. 2A, B, 2). In parallel, it was observed that the rise in RNS production in mitochondria was accompanied by the dose-dependent increase in hydroperoxide formation (Fig. 2C).

Unlike this, only moderate increase in the amount of metabolites was detected in the whole (intact) tissue. So, in the liver $\mathrm{NO}_{3}{ }^{-}$content rose from $0.120 \pm 0.008$ to only $0.180 \pm$ $0.02 \mu \mathrm{mol} \cdot \mathrm{mg}^{-1}$ relative to the increase from $0.035 \pm 0.01$ to $0.90 \pm 0.01 \mu \mathrm{mol} \cdot \mathrm{mg}^{-1}$ obtained in liver mitochondria. In the same way, the rise in $S$-nitrosothiols content from $1.20 \pm 0.04$ to $2.0 \pm 0.03 \mathrm{nmol} \cdot \mathrm{mg}^{-1}$ in liver relative to that from $0.80 \pm 0.08$ to $2.50 \pm 0.1 \mathrm{nmol} \cdot \mathrm{mg}^{-1}$ in liver mitochondria was found. The change in $\mathrm{NO}_{2}{ }^{-}$content in liver after $\mathrm{NG}$ administration was statistically insignificant, contrary to threefold increase of it in liver mitochondria (Fig. 2A, 2). In the case of $\mathrm{H}_{2} \mathrm{O}_{2}$, the effect of $\mathrm{NG}$ again was specifically localized to mitochondria. So, the increase in $\mathrm{H}_{2} \mathrm{O}_{2}$ content from $0.090 \pm 0.007$ to $0.30 \pm 0.01$ and from $0.050 \pm 0.006$ to 0.80 $\pm 0.008 \mathrm{nmol} \cdot \mathrm{mg}^{-1}$ in heart and liver mitochondria was detected $5 \mathrm{~min}$ after NG injection, against statistically insignificant increase of hydroperoxide production in liver tissue, which remained close to basal level. This proved that effect of NG was much more specific for mitochondrial than whole cell RNS metabolism and showed that NG administration in vivo resulted in the instant dose-dependent activation of mitochondrial RNS and ROS production. 


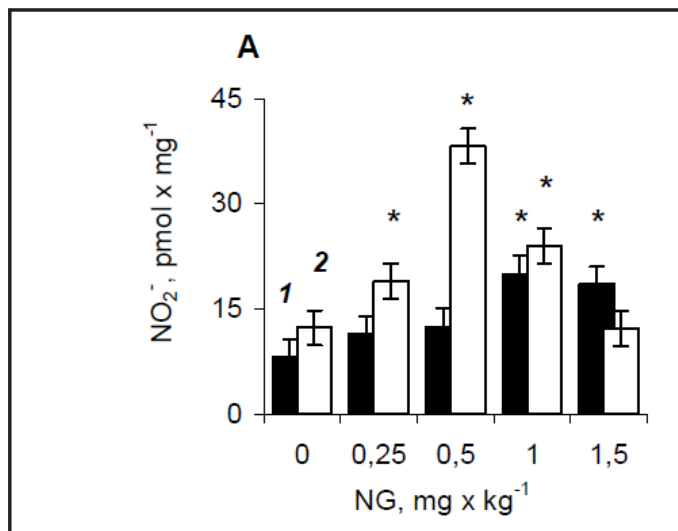

Fig. 2. The effect of NG on RNS and ROS production in rat heart (1) and liver (2) mitochondria. The content of $\mathrm{NO}_{2}^{-}$, pmol $\cdot \mathrm{mg}^{-1}(\mathrm{~A})$, S-nitrosothiols, $\mathrm{nmol} \cdot \mathrm{mg}^{-1}$ (B) and hydroperoxide, $\mathrm{nmol} \cdot \mathrm{mg}^{-1}$ (C) in mitochondria was determined 5 min after NG administration. The data were expressed as the mean $\pm \mathrm{SE}(\mathrm{M} \pm \mathrm{m}, \mathrm{n}=6) ; \mathrm{p}<0.05$ was considered to be statistically significant $(*)$.
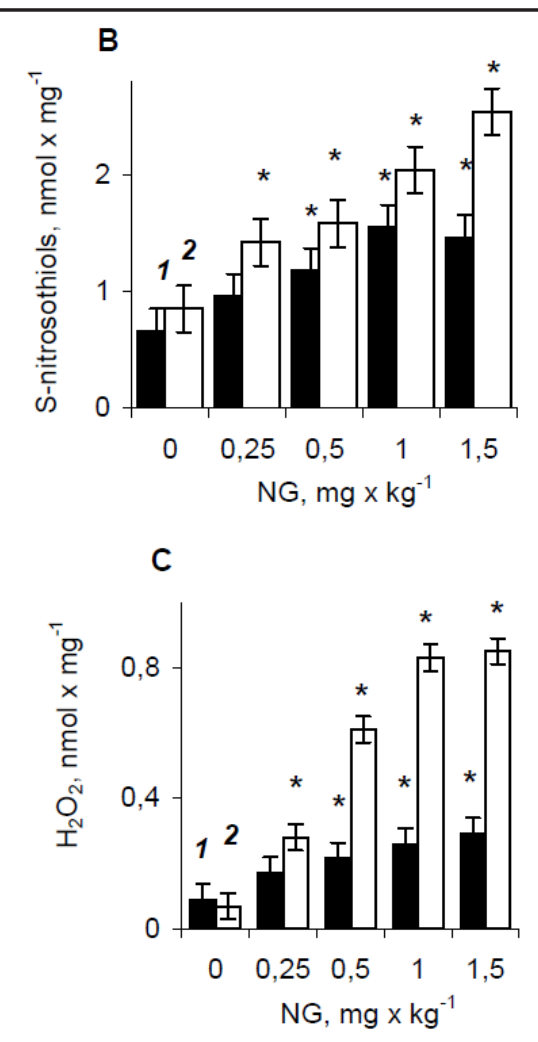

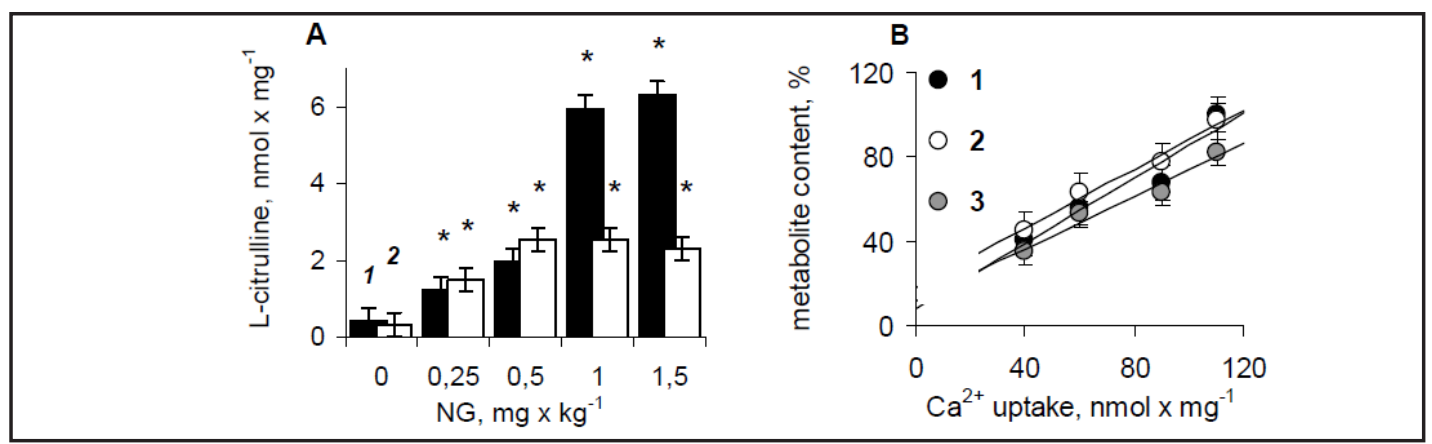

Fig. 3. The effect of NG on mtNOS activity in mitochondria. A - the content of L-citrulline, $\mathrm{nmol} \cdot \mathrm{mg}^{-1}$ in rat heart (1) and liver (2) mitochondria was determined 5 min after NG administration. B - correlation dependences of RNS and ROS production on $\mathrm{Ca}^{2+}$ uptake in heart mitochondria; the amounts of $\mathrm{NO}_{2}{ }^{-}(1), S$ nitrosothiols (2) and hydroperoxide (3) were expressed as percent of their maximum values. The data were expressed as the mean $\pm S E(M \pm m, n=6) ; p<0.05$ was considered to be statistically significant $(*)$.

$m$ tNOS activity is increased under the action of $N G$

The primary source of RNS is NO synthase (NOS) activity. Mitochondria are known to possess its own NOS (mtNOS) which is $\mathrm{Ca}^{2+}$-dependent isoform of the enzyme [15]. Thus, it was of especial interest to assess mtNOS activity under the action of NG in the living organism. With this aim, the amount of L-citrulline, the stable product of enzymatic NOS activity, was determined.

As previously, the effect observed in heart mitochondria resembled that obtained in liver mitochondria. Thus, rapid dose-dependent rise in L-citrulline content from $0.45 \pm 0.05$ $\mathrm{nmol} \cdot \mathrm{mg}^{-1}$ to $6.3 \pm 0.1 \mathrm{nmol} \cdot \mathrm{mg}^{-1}$ in heart mitochondria (Fig. 3A, 1) and from $0.45 \pm 0.06$ $\mathrm{nmol} \cdot \mathrm{mg}^{-1}$ to $2.5 \pm 0.08 \mathrm{nmol} \cdot \mathrm{mg}^{-1}$ in liver mitochondria (Fig. 3A, 2) was found. Such an increment in L-citrulline formation (5.6 times in liver mitochondria and 14.0 times in heart mitochondria) gave convincing evidence of mtNOS activation just starting from NG injection. 
In the literature, it was shown that mitochondrial NO production was dependent on $\mathrm{Ca}^{2+}$ accumulation in mitochondria of vascular endothelium cells [20]. In our experiments, the increase in RNS production in heart and liver mitochondria also took place along with the increase in $\mathrm{Ca}^{2+}$ accumulation capacity (Fig. 1-2). For this reason, the activation of mtNOS by $\mathrm{Ca}^{2+}$ accumulation in the matrix appears to be a plausible explanation for the activation of mitochondrial RNS metabolism. The reliability of this assumption was supported by the correlation established between the dose-dependent increase in $\mathrm{Ca}^{2+}$-uptake and RNS production under the action of moderate $\left(\leq 1.0 \mathrm{mg} \cdot \mathrm{kg}^{-1}\right)$ doses of NG (Fig. 3B). Based on the data, linear dependences of $\mathrm{NO}_{2}^{-}$and $S$-nitrosothiols content on $\mathrm{Ca}^{2+}$ uptake in heart mitochondria were obtained (Fig. 3B, 1,2). Similar to RNS, $\mathrm{H}_{2} \mathrm{O}_{2}$ formation too showed the dependence on matrix $\mathrm{Ca}^{2+}$ accumulation (Fig. 3B, 3).

Thus, the activation of metabolic processes in mitochondria was in a good agreement with short-term dose-dependent increase of $\mathrm{Ca}^{2+}$ uptake (Fig. 1A, B). This allows hypothesize that the rise in matrix calcium might be the direct cause for the activation of mtNOS and RNS metabolism in mitochondria of the living organism. In support of this assumption, the decrease of $\mathrm{NO}_{3}{ }^{-}$formation was observed along with the reduced uptake of $\mathrm{Ca}^{2+} 30 \mathrm{~min}$ after NG administration (Fig. 1A-D, 2).

NO enhances $\mathrm{Ca}^{2+}$ uptake in mitochondria in vivo due to the blockage of mitochondrial permeability transition pore

In agreement with the published data [7, 9], nitric oxide in vitro prevented uptake of calcium because of mitochondrial depolarization. Unlike this, NG administration in vivo potently activated $\mathrm{Ca}^{2+}$ accumulation in rat heart and liver mitochondria (Fig. 1A, B). Membrane potential $\left(\Delta \Psi_{\mathrm{m}}\right)$ in vivo was unaffected by moderate doses of $\mathrm{NG}$, but exceeding $1 \mathrm{mg} \cdot \mathrm{kg}^{-1}$, slight depolarization (by $\sim 20 \%$ ) was observed. Nevertheless, this coincided with the peak effects of $\mathrm{NO}$ on $\mathrm{Ca}^{2+}$ uptake and RNS production at $\sim 1 \mathrm{mg} \cdot \mathrm{kg}^{-1} \mathrm{NG}$ (Fig. $1 \mathrm{~A}, \mathrm{~B}$ ).

Calcium accumulation capacity of mitochondria is considered to be dependent on the equilibrium between uptake and the efflux of the cation [4]. The main component of $\mathrm{Ca}^{2+}$ uptake system is mitochondrial $\mathrm{Ca}^{2+}$-uniporter, whereas $\mathrm{Na}^{+} / \mathrm{Ca}^{2+}$ and $\mathrm{H}^{+} / \mathrm{Ca}^{2+}$ exchangers serve for $\mathrm{Ca}^{2+}$-efflux $[4,18]$. Convincing data support the notion that in sub-conductance states MPTP too could function as a $\mathrm{Ca}^{2+}$-releasing channel to prevent $\mathrm{Ca}^{2+}$-overload of mitochondria in a living organism [3, 27-29]. The ability of mitochondria to take up $\mathrm{Ca}^{2+}$ was shown to be essentially dependent on MPTP activity. So, MPTP blockage by cyclosporine A increased $\mathrm{Ca}^{2+}$ uptake in rat heart mitochondria under reperfusion conditions [30], and, on the contrary, mitochondrial uptake of $\mathrm{Ca}^{2+}$ greatly diminished along with the increase of MPTP activity with ageing [29], which show MPTP to be physiologically relevant $\mathrm{Ca}^{2+}$-efflux pathway. In our experiments, NO-donor treatment in vivo resulted in twofold increase of $\mathrm{Ca}^{2+}$ uptake in liver mitochondria, from $\sim 90$ to $\sim 180-200 \mathrm{nmol} \mathrm{Ca}{ }^{2+} \cdot \mathrm{mg}^{-1}$, the same as it was observed under the action of MPTP blocker cyclosporine A in vitro (from 100 to 200 nmol $\mathrm{Ca}^{2+} \cdot \mathrm{mg}^{-1}$ ). So, for better understanding the effect of NO on calcium accumulation, a direct study of NO action on $\mathrm{Ca}^{2+}$-uniporter and MPTP activity as most essential for matrix $\mathrm{Ca}^{2+}$ accumulation was conducted. With this purpose NO donors, sodium nitroprusside (SNP) and NG, were used.

To test whether the direct action of $\mathrm{NO}$ on mitochondrial $\mathrm{Ca}^{2+}$-uptake system could contribute to the overall increase in $\mathrm{Ca}^{2+}$ uptake, we studied the effect of NO donors on $\mathrm{Ca}^{2+}$-uniporter activity. With the notion that NO could depolarize mitochondria because of the blockage of respiratory chain [7-9], the effect of NO donors on mitochondrial $\mathrm{Ca}^{2+}-$ uniporter activity was assessed from its dependence on membrane potential [18], in the presence of MPTP blocker cyclosporine A. With this aim, the initial rates of $\mathrm{Ca}^{2+}$ uptake $\left(V_{0}\right)$ were determined under membrane depolarization induced by increasing concentrations of SNP, NG and malonate in mitochondria respiring on succinate. Obtained values were plotted against membrane potential, measured in parallel under the same conditions (Fig. 4).

According to our experiments, the initial rate of $\mathrm{Ca}^{2+}$ uptake in energized liver mitochondria taken for $100 \%$ in the absence of NO donors and malonate was $280 \pm 12$ 
Fig. 4. The assessment of the effect of NO donors on $\mathrm{Ca}^{2+}$-uniporter activity. The initial rate $\left(V_{0}\right)$ of $\mathrm{Ca}^{2+}$ uptake in rat liver mitochondria under the action of SNP (1), NG (2), and malonate (3) was determined in parallel with membrane potential $\left(\Delta \Psi_{\mathrm{m}}\right)$. On the ordinate axis: initial rate of $\mathrm{Ca}^{2+}$-uptake $\left(V_{0}\right)$; on the abscissa axis: $\Delta \Psi_{\mathrm{m}}$ at different concentrations of SNP, $\mathrm{NG}$ and malonate in mitochondria respiring on succinate. $V_{0}$ of $\mathrm{Ca}^{2+}$-uptake and $\Delta \Psi_{\mathrm{m}}$ in the absence of NO donors and malonate was taken for $100 \%$. $\mathrm{Ca}^{2+}$ was added into standard incubation medium at 50 $\mathrm{nmol} \cdot \mathrm{mg}^{-1}$. The data represent mean $\pm \mathrm{SD}$.
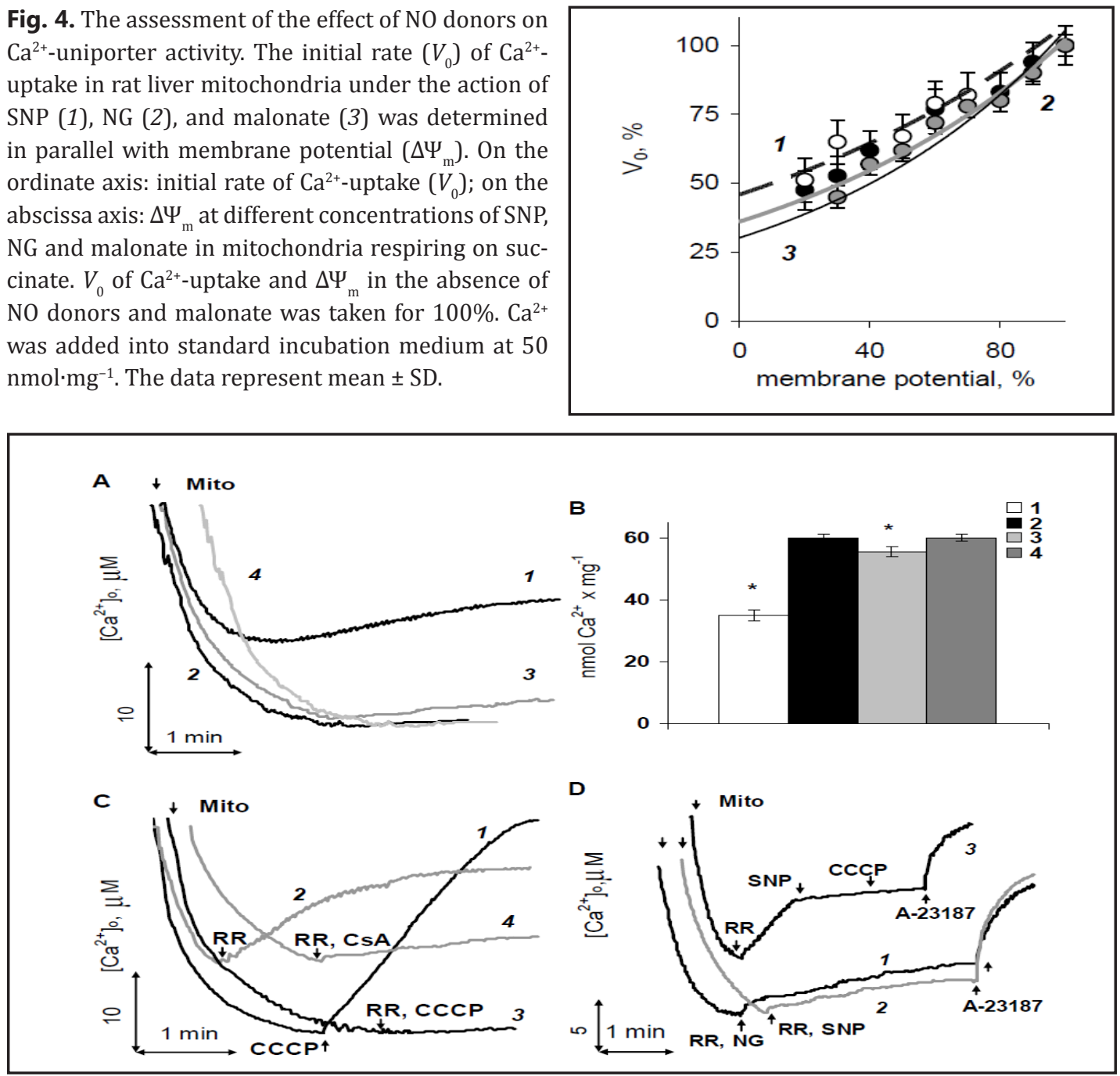

Fig. 5. The effect of NO donors on MPTP activity: representative time traces (A) and peak $\mathrm{Ca}^{2+}$ uptake (B) in mitochondria of control animals $(A, 1,2)$ and treated by $\mathrm{NG}, 1 \mathrm{mg} \cdot \mathrm{kg}^{-1}(\mathrm{~A}, 3,4$, grey color $)$ in the absence $(\mathrm{A}$, $B, 1,3)$ and the presence $(A, B, 2,4)$ of cyclosporine A (CsA); C - RR-sensitive $(1,3)$ and RR-insensitive $(2,4)$ $\mathrm{Ca}^{2+}$ transport after the addition of CCCP $(1,3), \mathrm{RR}(2-4)$ and $10^{-6} \mathrm{M}$ CsA (4) as shown by the arrows; D - the effect of NO on RR-insensitive $\mathrm{Ca}^{2+}$-efflux; the additions of $10^{-5} \mathrm{M}$ RR (1-3), $10^{-4} \mathrm{M} \mathrm{NG}(1), 5 \cdot 10^{-4} \mathrm{M}$ SNP $(2,3)$, $10^{-6} \mathrm{M}$ of $\mathrm{Ca}^{2+}$-ionophore A-23187 (1-3), and $10^{-6} \mathrm{M} \mathrm{CCCP} \mathrm{(3)} \mathrm{were} \mathrm{as} \mathrm{shown.} \mathrm{CaCl}_{2}$ was added into standard incubation medium at $30 \mu \mathrm{M}$; mitochondria were added at $0.5 \mathrm{mg} \cdot \mathrm{ml}^{-1}$; CsA was added at $10^{-6} \mathrm{M}(\mathrm{A}, \mathrm{B}, 2$, 4; $\mathrm{C}, 1,3)$; peak $\mathrm{Ca}^{2+}$ uptake in $\mathrm{nmol} \cdot \mathrm{mg}^{-1}(\mathrm{~B})$ is shown as mean $\pm \mathrm{SE}(*-\mathrm{P}<0.05)$. On the ordinate axis: $\mathrm{Ca}^{2+}$ concentration in the medium, $\left[\mathrm{Ca}^{2+}\right]_{0}, \mu \mathrm{M}$.

$\mathrm{nmol} \cdot \mathrm{min}^{-1} \cdot \mathrm{mg}^{-1}$. It declined exponentially with the decrease of $\Delta \Psi_{\mathrm{m}}$ which agreed with the literature [18]. The differences between the dependences of $\mathrm{Ca}^{2+}$-uniporter activity on $\Delta \Psi_{\mathrm{m}}$ in all cases were statistically insignificant (Fig. 4, 1-3), thus we came to the conclusion that $\mathrm{Ca}^{2+}$-uniporter was not affected by nitric oxide and was not responsible for the increase in $\mathrm{Ca}^{2+}$ accumulation capacity.

To explain the improvement of $\mathrm{Ca}^{2+}$ accumulation capacity under NG treatment, we supposed further that MPTP activity could be affected by NO. Analogous time traces, representative of $\mathrm{Ca}^{2+}$ transport in isolated mitochondria, show that properties of $\mathrm{Ca}^{2+}$ transport were changed in NO treated animals (at $1 \mathrm{mg} \cdot \mathrm{kg}^{-1} \mathrm{NG}$ ). So, in control animals $\mathrm{Ca}^{2+}$ uptake typically was followed by $\mathrm{Ca}^{2+}$ efflux sensitive to cyclosporine $\mathrm{A}$, which diminished related peak $\mathrm{Ca}^{2+}$ accumulation (Fig. 5A, B, 1,2). Unlike this, after NO-treatment cyclosporine 
A-sensitive $\mathrm{Ca}^{2+}$ efflux was considerably suppressed, while peak $\mathrm{Ca}^{2+}$ uptake increased almost to control level (Fig. 5A, B, 3, 4), which directly indicated MPTP inhibition by NO in vivo. To prove this observation more, we studied direct effect of NO donors on MPTP activity.

As showed kinetic curves, RR-sensitive and RR-insensitive $\mathrm{Ca}^{2+}$ transport were the main pathways of $\mathrm{Ca}^{2+}$ efflux from mitochondria under experimental conditions (Fig. 5C, 1,2). Mitochondrial depolarization by CCCP in the presence of cyclosporine A delivered all $\mathrm{Ca}^{2+}$ taken up by mitochondria via $\mathrm{Ca}^{2+}$ uniporter in RR-sensitive way (Fig. 5C, 1, 3). In the presence of cyclosporine A CCCP-induced $\mathrm{Ca}^{2+}$ efflux was instantly blocked any time since the addition of RR to the suspension (not shown). $\mathrm{Ca}^{2+}$ release from energized mitochondria required the blockage of $\mathrm{Ca}^{2+}$ uniporter by $\mathrm{RR}$ (Fig. 5C, 2). Most part of RR-insensitive $\mathrm{Ca}^{2+}$ transport was blocked by cyclosporine A (Fig. 5C, 2, 4), which allowed to assess MPTP activity from RR-insensitive $\mathrm{Ca}^{2+}$ efflux. With this aim RR was added after $\mathrm{Ca}^{2+}$ accumulation, and the effects of NO donors on MPTP activity were studied (Fig. 5D). To exclude the contribution of $\mathrm{Na}^{+} / \mathrm{Ca}^{2+}$ and $\mathrm{H}^{+} / \mathrm{Ca}^{2+}$ exchangers to RR-insensitive $\mathrm{Ca}^{2+}$ efflux, only cyclosporine A-sensitive component of $\mathrm{Ca}^{2+}$ transport was taken into account. Such an approach allowed avoiding possible effects of membrane depolarization caused by $\mathrm{NO}$ on $\mathrm{Ca}^{2+}$ uptake and thus MPTP activity [9].

Unlike the case with $\mathrm{Ca}^{2+}$ uniporter, nitric oxide proved to be effective MPTP blocker (Fig. 5D). Both NO donors, SNP and NG almost completely inhibited MPTP activity at concentrations $\geq 5 \cdot 10^{-4} \mathrm{M}$ (Fig. 5D, 1,2). MPTP blockage occurred at once since the addition of NO donor into incubation medium (Fig. 5D, 3), and the blockage of $\mathrm{Ca}^{2+}$ transport in all cases was bypassed by the addition of $\mathrm{Ca}^{2+}$-ionophore, A-23187 (Fig. 5D). The use of chemically different compounds as NO donors ensured that observed effects may be ascribed to the action of nitric oxide.

Unlike MPTP, other $\mathrm{Ca}^{2+}$ efflux pathways were little effective in releasing calcium from mitochondria, which was seen from the low rate of RR-insensitive $\mathrm{Ca}^{2+}$ efflux in the presence of cyclosporine A (Fig. 5C, 4). Thus we came to the conclusion that MPTP blockage by nitric oxide was the major cause for the increase in $\mathrm{Ca}^{2+}$ uptake under $\mathrm{NG}$ administration in vivo. This, in turn, resulted in a strong activation of mtNOS and mitochondrial RNS metabolism accompanied by the increase in ROS production.

\section{Discussion}

The effect of nitric oxide on mitochondrial calcium accumulation

In this work, it was shown that administration of NO donor nitroglycerine resulted in remarkable increase in calcium accumulation capacity of rat heart and liver mitochondria because of MPTP blockage by NO. Increased mitochondrial ability to take up calcium correlated with the activation of mtNOS and the rise in mitochondrial RNS production, shown to be preferably localized in mitochondria. The activation of RNS metabolism resulted in high level of protein nitrosylation supposed to contribute to MPTP inhibition under NOdonor administration.

The pattern of calcium accumulation in mitochondria isolated from NO-treated animals exhibited suppressed MPTP activity (Fig. 5A, 3, 4). Study in vitro confirmed that MPTP could be effectively blocked by NO (Fig. 5D), while uniporter activity was not affected (Fig. 4). In our experiments, mitochondrial $\mathrm{Ca}^{2+}$ buffering properties for the most part were dependent on $\mathrm{Ca}^{2+}$-uniporter and MPTP activity, the contribution of other $\mathrm{Ca}^{2+}$ efflux pathways (such as $\mathrm{Na}^{+} / \mathrm{Ca}^{2+}$ and $\mathrm{H}^{+} / \mathrm{Ca}^{2+}$ exchangers [18] or non-specific $\mathrm{Ca}^{2+}$ efflux due to the presence of fatty acids in mitochondrial membrane [31]) being quite negligible. Unlike indirect MPTP inhibition by nitric oxide caused by membrane depolarization and prevention of $\mathrm{Ca}^{2+}$ uptake [9], our data gave the evidence for the instant MPTP blockage since the addition of NO donor to the medium (Fig. 5D). This implies the direct mechanisms of MPTP blockage by NO. But thus far, molecular mechanisms of NO interaction with MPTP remain obscure.

MPTP activity is known to be strongly dependent on the redox state of pyridine nucleotides and functionally active thiol groups [32]. NO can react with SH-groups of 
several proteins and enzymes with the formation of derivatives such as mixed disulfides, sulphonic and sulphenic acids, and $S$-nitrosothiols resulting in the loss of the enzyme activity $[24,33]$. Recently it was shown that nitrosylation of Cys-203 of cyclophilline D inhibited MPTP opening [34]. Thus, critical thiol modification of MPTP or regulatory protein(s) may serve a plausible explanation for observed blockage of MPTP activity both in vitro and in vivo. Accordingly, high level of chemically modified (nitrosylated) proteins and other NO derivatives in mitochondria of NG-treated animals (Fig. 2B) allowed us to assume that that direct action of NO/RNS on the pore or adjacent protein moiety could contribute to its inhibition in the living organism.

Nitroglycerine becomes physiologically active as NO donor after the hydrolysis of $\mathrm{NO}_{3}{ }^{-}$group with its following reduction to $\mathrm{NO}$ [35], and the rise in $\mathrm{NO}_{3}{ }^{-}$formation starting from NG injection (Fig. 1C, D, 1) largely may be caused by intracellular biotransformation of this drug. Thus, elevated matrix calcium could not be solely responsible for the increase in RNS production. On the other hand, instant dose-dependent activation of mtNOS, and mitochondrial localization of metabolic processes definitely indicated mitochondria as the primary source of RNS under the action of NG. In the literature, the activation of mtNOS was shown to occur due to $\mathrm{Ca}^{2+}$ accumulation in vitro [20]. Because mtNOS is known to be the main source of mitochondrial RNS [13-15], mtNOS activation along with the increase in $\mathrm{Ca}^{2+}$ uptake might reliably explain the rise in RNS production under NG administration (Fig. 2, 3).

Most part of hydroperoxide production under the action of NG too was of mitochondrial origin (Fig. 2C); however, at present it is rather difficult to indicate precisely the sources of $\mathrm{H}_{2} \mathrm{O}_{2}$. Besides the respiratory chain, mitochondria possess too many sources of ROS, and several $\mathrm{Ca}^{2+}$-dependent enzymes, including mtNOS, could contribute to ROS production [12-17]. The one plausible cause for the increase in hydroperoxide formation is high level of $S$-nitrosothiols (Fig. 2B), capable to inhibit the respiratory chain and promote ROS production [33]. Thus, observed rise in $S$-nitrosothiol formation after NG administration was coincident with partial ( $\sim 20 \%)$ depolarization of mitochondria at the doses $\geq 1 \mathrm{mg} \cdot \mathrm{kg}^{-1}$ NG. Increase in $\mathrm{Ca}^{2+}$ uptake too could be one of the major causes for the enhancement of hydroperoxide production. Earlier we have shown that $\mathrm{Ca}^{2+}$ uptake critically increased ROS production in isolated brain mitochondria [36]. So it was reasonable to suppose close effect of calcium in heart and liver mitochondria under the action of NG in vivo. This assumption was confirmed by the correlation established between $\mathrm{Ca}^{2+}$ accumulation and the activation of ROS metabolism (Fig. 3B); however, it needs to be verified by more detailed studies.

\section{Physiological implications}

Mitochondria are central in pathogenesis of cardiac and neurodegenerative diseases because of ROS overproduction, MPTP opening and impaired $\mathrm{Ca}^{2+}$-buffering capacity [10, 30, 37]. MPTP exhibits several conductance states [11, 38, 39] with different permeability to solutes. Convincing data support the notion that in sub-conductance states MPTP could function as $\mathrm{Ca}^{2+}$-releasing channel $[11,27,28]$, and MPTP flickering between the open and closed state is supposed to be relevant under physiologically normal conditions [38-40]. This is in agreement with its function as cyclosporine A-sensitive pathway of $\mathrm{Ca}^{2+}$ efflux (Fig. 5D). Because at moderate doses in vivo NG did not impair mitochondrial energy state, physiologically, MPTP blockage by NO means the improvement of $\mathrm{Ca}^{2+}$ buffering capacity of mitochondria (Fig. 1 B; 5 B, 1, 3). Thus, physiological meaning of MPTP blockage by NO in vivo is: 1) suppression of MPTP activity as $\mathrm{Ca}^{2+}$-releasing channel; 2) increase in $\mathrm{Ca}^{2+}$ buffering capacity of mitochondria, which help the removal of $\mathrm{Ca}^{2+}$ from cytosol; 3) prevention of MPTP transition to high conductance states and suppression of apoptosis induction. It is tempting to speculate that rise in mtNOS activity and RNS production caused by elevated matrix $\mathrm{Ca}^{2+}$ could serve a sort of feedback mechanism aimed to keep MPTP in a closed state and contribute to beneficial therapeutic action of nitric oxide.

The crosstalk between nitric oxide, calcium and ROS in mitochondria has many both physiological and pathophysiological aspects, which are not very well understood yet. In our work too, not all effects of NO donor in mitochondria were purely beneficial. So, the 


\section{Cellular Physiology Cell Physiol Biochem 2016;39:193-204 \begin{tabular}{l|l|l}
\hline DOI: 10.1159/000445616 & $\begin{array}{l}\text { C } 2016 \text { The Author(s). Published by S. Karger AG, Basel } \\
\text { www.karger.com/cpb }\end{array}$ \\
\hline
\end{tabular}}

reverse of MPTP blockage was calcium overload of mitochondria, simultaneous with ROS overproduction, seen in our experiments. Possibly, it may be overcome by mitochondrial antioxidant system, but this issue needs further studies.

Based on the data obtained, we came to the conclusion that improved matrix $\mathrm{Ca}^{2+}$ accumulation, together with MPTP blockage, are important contributions to vasodilatory and anti-apoptotic action of NO under pathophysiological conditions. So we consider that results of our work could serve better understanding of the mechanisms underlying cardioprotective effects of NO donors in clinics.

\section{Disclosure Statement}

The authors declare no conflict of interest.

\section{References}

1 O'Donnell ME, Owen NE: Regulation of ion pumps and carriers in vascular smooth muscle. Physiol Rev 1994;74:683-721.

2 Yuan X-J, Tod ML, Rubin LJ, Blaustein MP: NO hyperpolarizes pulmonary artery smoth muscle cells and decreases the intracellular Ca2+ concentration by activating voltage-gated $\mathrm{K}+$ channels. Proc Natl Acad Sci USA 1996;93:10489-10494.

3 Barsukova A, Komarov A, Hajnoczky G, Bernardi P, Bourdette D, Forte M: Activation of the mitochondrial permeability transition pore modulates $\mathrm{Ca} 2+$ responses to physiological stimuli in adult neurons Eur J Neurosci 2011;33:831-842.

4 Rizzuto R, De Stefani D, Raffaello A, Mammucari C: Mitochondria as sensors and regulators of calcium signaling. Mol Cell Biol 2012;13:566-578.

5 Szabadkai G, Rizzuto R Participation of endoplasmic reticulum and mitochondrial calcium handling in apoptosis: more than just neighborhood? FEBS Lett 2004;567:111-115.

6 Xie Y, Xiao F, Luo L, Zhong C: Activation of autophagy protects against ROS-mediated mitochondriadependent apoptosis in L-02 hepatocytes induced by Cr(VI). Cell Physiol Biochem 2014;33:705-716.

7 Schweizer M, Richter Ch: Nitric oxide potently and reversibly deenergizes mitochondria at low oxygen tension. Biochem Biophys Res Commun 1994;204:169-175.

8 Rakhit RD, Mojet MH, Marber MS, Duchen MR: Mitochondria as targets for nitric oxide-induced protection during simulated ischemia and reoxygenation in isolated neonatal cardiomyocytes. Circulation 2001;103:2617-2623.

9 Brookes PS, Salinas EP, Darley-Usmar K, Eiserich JP, Freeman BA, Darley-Usmar VM, Anderson PG: Concentration-dependent effects of nitric oxide on mitochondrial permeability transition and cytochrome c release. J Biol Chem 2000;275:20474-20479.

10 Halestrap AP, Kerr PM, Javadov S, Woodfield KY: Elucidating the molecular mechanism of the permeability transition pore and its role in reperfusion injury of the heart. Biochim Biophys Acta 1998;1366:79-94.

11 Bernardi P, Rasola A, Forte M, Lippe G: The mitochondrial permeability transition pore: channel formation by F-ATP synthase, integration in signal transduction, and role in pathophysiology. Physiol Rev 2015;95:1111-1155.

12 Brookes PS, Yoon Y, Robotham JL, Anders MW, Sheu SS: Calcium, ATP, and ROS: a mitochondrial love-hate triangle. Am J Physiol 2004;287:C817-C833.

13 Feissner RF, Skalska J, Gaum WE, Sheu SS: Crosstalk signaling between mitochondrial Ca2+ and ROS. Front Biosci 2009;14:1197-1218.

14 Csordas G, Hajnoczky G: SR/ER-mitochondrial local communication: calcium and ROS. Biochim Biophys Acta 2009;1787:1352-1362.

15 Brookes PS: Mitochondrial nitric oxide synthase. Mitochondrion 2004;3:187-204.

16 Murphy MP: How mitochondria produce reactive oxygen species. Biochem J 2009;417:1-13.

17 Klatt P, Schmidt K, Uray G, Mayer B: Multiple catalytic functions of brain nitric oxide synthase. Biochemical characterization, cofactor requirement, and the role of $\mathrm{N} \omega$-hydroxy-L-arginine as an intermediate. J Biol Chem 1993;268:14781-14787. 


\section{Cellular Physiology Cell Physiol Biochem 2016;39:193-204 \begin{tabular}{l|l|l|l}
\hline DOI: 10.1159/000445616 & (c)16 The Author(s). Published by S. Karger AG, Basel \\
\hline
\end{tabular} and Biochemistry Published online: June 24, 2016 www.karger.com/cpb}

18 Gunter TE, Sheu SS: Characteristics and possible functions of mitochondrial $\mathrm{Ca}(2+)$ transport mechanisms. Biochim Biophys Acta 2009;1787:1291-1308.

19 McCormak JG, Denton RM: Mitochondrial Ca2+ transport and the role of intramitochondrial Ca2+ in the regulation of energy metabolism. Dev Neurosci 1993;15:165-173.

20 Dedkova EN, Ji X, Lipsius SL, Blatter LA: Mitochondrial calcium uptake stimulates nitric oxide production in mitochondria of bovine vascular endothelial cells. Am J Physiol 2004;286:C406-C415.

21 Åkerman KEO, Wikström MKF: Safranine as a probe of the mitochondrial membrane potential. FEBS Lett 1976;68:191-197.

22 Green LC, Wagner DA, Glogowski J, Skipper PL, Wishnok JS, Tannenbaum SR: Analysis of nitrite, nitrate and [15N]nitrate in biological fluids. Anal Biochem 1982;126:131-138.

23 Pfeiffer S, Gorren ACF, Schmidt K, Werner ER, Hansert B, Bohle DS, Mayer B: Metabolic fate of peroxynitrite in aqueous solution. J Biol Chem 1997;272:3465-3470.

24 Percival MD, Ouellet M, Campagnolo Ch, Claveau D, Li Ch: Inhibition of cathepsin K by nitric oxide donors: evidence for the formation of mixed disulfides and a sulfenic acid. Biochemistry 1999;38:13574-13583.

25 Buga GM, Singh R, Pervin S, Rogers NE, Schmitz DA, Jenkinson CP, Cederbaum SD, Ignarro LJ: Arginase activity in endothelial cells: inhibition by NG-hydroxy-L-arginine during high-output NO production. Am J Physiol 1996;271:H1988-H1998.

26 Huwiler M, Kohler H: Pseudo-catalytic degradation of hydrogen peroxide in the lactoperoxidase/H2O2/ iodide system. Eur J Biochem 1984;141:69-74.

27 Bernardi P, von Stockum S: The permeability transition pore a Ca2+ release channel: new answers to an old question. Cell Calcium 2012;52:22-27.

28 von Stockum S, Giorgio V, Trevisan E, Lippe G, Glick GD, Forte MA, Da-Re C, Checchetto V, Mazzotta G, Costa R, Szabo I, Bernardi PF: ATPase of D. melanogaster forms 53 picosiemen (53-pS) channels responsible for mitochondrial Ca2+-induced Ca2+ release. J Biol Chem 2015;290:4537-4544.

29 Mather M, Rottenberg H: Ageing enhances the activation of the permeability transition pore in mitochondria. Biochem Biophys Res Commun 2000;273:603-608.

30 De Paulis D, Chiari P, Teixeira G, Couture-Lepetit E, Abrial M, Argaud L, Gharib A, Ovize M: Cyclosporine A at reperfusion fails to reduce infarct size in the in vivo rat heart. Basic Res Cardiol 2013;108:379-390.

31 Broekemeier KM, Schmid PC, Schmid HHO, Pfeiffer DR: Effects of phospholipase A2 inhibitors on ruthenium red-induced Ca2+ release from mitochondria. J Biol Chem 1985;260:105-113.

32 Chernyak BV, Bernardi P: The mitochondrial permeability transition pore is modulated by oxidative agents through both pyridine nucleotides and glutathione at two separate sites. Eur J Biochem 1996;238:623-630.

33 Borutaite V, Brown GC: S-nitrosothiol inhibition of mitochondrial complex I causes a reversible increase in mitochondrial hydrogen peroxide production. Biochim Biophys Acta 2006;1757:562-566.

34 Nguyen TT, Stevens MV, Kohr M, Steenbergen C, Sack MN, Murphy E: Cysteine 203 of cyclophilin D is critical for cyclophilin D activation of the mitochondrial permeability transition pore. J Biol Chem 2011;286:40184-40192.

35 Ignarro LJ, Napoli C, Loscalzo J: Nitric oxide donors and cardiovascular agents modulating the bioactivity of nitric oxide. Circ Res 2002;90:P.21-28.

36 Akopova OV, Kolchinskaya LI, Nosar VI, Bouryi VA, Mankovska IN, Sagach VF: Effect of potential-dependent potassium uptake on production of reactive oxygen species in rat brain mitochondria. Biochemistry (Moscow) 2014;79:44-53.

37 Wang R, Liu Y, Liu X, Jia Sh, Zhao J, Cui D, Wang L: Resveratrol protects neurons and the myocardium by reducing oxidative stress and ameliorating mitochondria damage in a cerebral ischemia rat model. Cell Physiol Biochem 2014;34:854-864.

38 Zoratti M, De Marchi U, Gulbins E, Szabo I: Novel channels of the inner mitochondrial membrane. Biochim Biophys Acta 2009;1787:351-363.

39 Huser J, Blatter LA: Fluctuations in mitochondrial membrane potential caused by repetitive gating of the permeability transition pore. Biochem J 1999;343:311-317.

40 Petronilli V, Miotto G, Canton M, Brini M, Colonna R, Bernardi P, Di Lisa F: Transient and long-lasting openings of the mitochondrial permeability transition pore can be monitored directly in intact cells by changes in mitochondrial calcein fluorescence. Biophys J 1999;76:725-734. 